\title{
Evaluation of a Computer-tailored Lifestyle Modification Support Tool for Employees in Japan
}

\author{
Hiroko FUJII'*, Makiko NAKADE ${ }^{2}$, Yasuo HARUYAMA ${ }^{1}$, Hiroshi FUKUDA ${ }^{3}$, \\ Michiyo HASHIMOTO ${ }^{1}$, Tadashi IKUYAMA ${ }^{4}$, Hironobu KABURAGI ${ }^{5}$, Eri MURAI ${ }^{5}$, \\ Masahiko OKUMURA ${ }^{6}$, Toshimi SAIRENCHI ${ }^{1}$ and Takashi MUTO' \\ ${ }^{1}$ Department of Public Health, Dokkyo Medical University School of Medicine, 880 Kitakobayashi, Mibu, \\ Shimotsuga, Tochigi 321-0293, Japan \\ ${ }^{2}$ Graduate School of Medicine, The University of Tokyo, 7-3-1 Hongo, Bunkyo, Tokyo 113-0033, Japan \\ ${ }^{3}$ Juntendo University School of Medicine, 2-1-1 Hongo, Bunkyo, Tokyo 113-8421, Japan \\ ${ }^{4}$ Yamano College of Aesthetic, 530 Yarimizu, Hachioji, Tokyo 192-0396, Japan \\ ${ }^{5}$ Secom Medical System Corporation, 1-5-1 Jingumae, Shibuya, Tokyo 150-0001, Japan \\ ${ }^{6}$ Secom IS Laboratory, 8-10-16 Simorennjyaku, Mitaka, Tokyo 181-9528, Japan
}

Received November 17, 2008 and accepted January 15, 2009

\begin{abstract}
To examine the effectiveness of a computer-tailored support tool for lifestyle modification developed for employees, we conducted an intervention study of pre-post test design. The program was based on principles of behavior science referring to goal setting processes, self monitoring, and feedback. The program of the support process was fully automated. A total of 650 participants of four workplaces in Japan completed the baseline assessment, 185 (28.5\%) of those returned for the post-test assessment 4 months later. There were significant improvements in lifestyle behaviors between baseline and post-test: In men, low energy intake $(p<0.01)$ and exercise frequency $(p<0.05)$, and in women, low salt intake $(p<0.05)$ and exercise frequency $(p<0.05)$. Furthermore, significant improvements were shown in the stage of change between baseline and post-test: Low salt intake $(p<0.01)$ and regular exercise in men $(p<0.01)$. Our results suggest a possibility that the program, utilizing a computer-tailored lifestyle modification support tool developed for use by employees, had a positive effect on participants' lifestyle behaviors in Japanese workplaces. The degree to which our results generalize to effects of the program is unclear but examination to develop more efficient and effective programs is warranted.
\end{abstract}

Key words: Computer-tailored, Lifestyle, Behavior, Workplace

\section{Introduction}

Lifestyle-related disease, which is caused by modifiable factors such as inappropriate diet, physical inactivity, smoking, etc., is a serious problem in Japan. Recently the mortality from lifestyle-related diseases accounted for almost $60 \%$ of all mortality, and the medical cost accounted for almost $30 \%$ of the total ${ }^{1}$. The workplace has been recognized as an important target for health promotion, as $57.9 \%$ of the total population aged $15 \mathrm{yr}$ or over was

*To whom correspondence should be addressed. employed in $\mathrm{Japan}^{2)}$.

In Japan, health education for prevention or management of lifestyle-related diseases at the workplace has been carried out mostly by face-to-face methods such as counselling, and previous studies have shown that these were effective on employees' health ${ }^{3-6)}$. However, the face-to-face approach has some problems in terms of manpower limitations, convenience of employees, and character of employees who prefer not to participate in faceto-face education. One solution to these problems is for support staff to use a non face-to-face approach to employees by means of ordinary mail ${ }^{7)}$, telephone, fax $^{8)}$, 
e-mail and web sites for delivering messages, and another solution is to use computer technology for analyzing a personal condition from questionnaires and making tailored messages ${ }^{9-11)}$. These methods make health support services more efficient and available.

Brug et al. reported that in a randomized workplace trial over about $6 \mathrm{wk}$, a significant effect of tailoring was found for decreased fat consumption and for attitudes and intentions toward reducing fat intake and increasing fruit and vegetable consumption ${ }^{12)}$. Campbell et al. reported that in a randomized study of female blue-collar employees, the significant effect of increasing fruit and vegetables consumption over 18 months ${ }^{13}$. However, in Japan, not much information is available on computer-tailored nutrition education programs in randomized control trials in the workplace ${ }^{14)}$. To the best of our knowledge, little has been reported on the effectiveness of fully automated computer-tailored health education that supported lifestyle modification focusing on dietary behavior and physical activity at workplaces in Japan.

A computer-based lifestyle modification support tool program, named "Health up $\mathrm{Navi}^{15)}$ (Secom Medical System Corporation)" was developed for use by employees in Japan. The program was based on principles of behavioral change ${ }^{16)}$, referring to goal setting processes, self monitoring, and feedback. The program of the support process was fully automated.

The purpose of this study was to clarify whether the lifestyle modification support tool with computer-tailoring yields desirable effects on lifestyle behaviors and consciousness, focusing on dietary habits and physical activity.

\section{Subjects and Methods}

\section{Participants and study design}

Approximately 30,000 employees at four workplaces in Japan were invited to participate in a program of computer-tailored lifestyle modification support. Advertisement of the study was conducted by posters, leaflets and invitations by public health nurses at the workplaces. A total of 650 employees, corresponding to $2 \%$ of the total number of eligible employees, were enrolled in the study using a pre-post test design. After the intervention, 185 participants, corresponding to $28.5 \%$ of baseline participants, completed the post-test survey. This study was conducted from 2006 to 2007.

Ethics approval was given by the ethics committee at Dokkyo Medical University, and informed consent was obtained from all participants via the computer system.

\section{Intervention program}

The program was comprised a computer-based lifestyle modification support tool program, named "Health up Navi ${ }^{15)}$ (Secom Medical System Corporation)", based on principles of behavioral science. The following was the process by which a participant addressed his/her self-management for prevention or improvement of lifestyle-related diseases.

(1) At baseline, each participant answered questionnaires about their physical state, including height and weight, present lifestyle factors and consciousness via a website on screens of personal computers or mobile phones. A weighing machine was not distributed to each participant.

(2) Computer-tailored advice based on their physical state, lifestyle or motivation for lifestyle modification, from the assessment of the baseline questionnaire was delivered to the participant via computers.

(3) Referring to the advice sent, the participant selected their own approach to changing their lifestyle, specifically to set tangible goals, such as using stairs instead of taking elevators or escalators, daily intake of fruits, and recording daily weight or number of steps walked. A pedometer was not distributed to each participant.

(4) The participant recorded daily data related to achieving their tangible goals. Based on the records, messages including graphic forms of their records were delivered via computer to encourage their behavior change for healthy lifestyle.

(5) After the intervention program for 4 (3-7) (median (range)) months, the participant answered a questionnaire similar to the baseline one.

\section{Evaluation measures}

With self-reported weight and height, body mass index (BMI) was calculated as weight $(\mathrm{kg})$ divided by height squared $\left(\mathrm{m}^{2}\right)$, and overweight was defined as those whose BMI was $25 \mathrm{~kg} / \mathrm{m}^{2}$ or over based on the criterion value for overweight in Japanese ${ }^{17}$. Smoking status was indicated using four categories: current daily smoker, current occasional smoker, former smoker and never smoked. Current smoker was defined as one who currently smokes daily or occasionally. Drinking status was confirmed by frequency of drinking and quantity of alcohol consumption. Habitual drinker was defined as one who takes more than approximately $20 \mathrm{~g}$ of alcohol per day for $3 \mathrm{~d}$ or more per week.

As outcome measures, potential behavioral determinants of dietary intake were assessed for low salt intake, low energy intake, vegetable/fruit intake, and healthy eating, separately. Each of them included 9, 3, 3, 5 items respectively and the details are shown in Table 1. Each item was categorized as yes or no. Each cut-off value of score on healthy lifestyle of dietary intake was defined by the median of all participants at baseline. Physical 
Table 1. The behavioral determinants of dietary intake in the present study

\begin{tabular}{|c|c|}
\hline Category & Item \\
\hline Low salt intake & $\begin{array}{l}\text { - Intake frequency of soup less than } 2 \text { times per day. } \\
\text { - Leaving some soup when you eat noodles. } \\
\text { - Intake frequency of salt-rich food, such as fish salted down, cod roe, ham, sausage, steamed fish paste less than } 3 \\
\text { times per week. } \\
\text { - Intake frequency of pickle or food boiled down in sweetened soy less than } 2 \text { times per day. } \\
\text { - Not putting sauce, such as soy sauce, salt, on food with flavor or pickles. } \\
\text { - Adding spice, such as juice pressed from bitter oranges, squeeze of lemon, pepper, red pepper, instead of soy sauce. } \\
\text { - Not having strong flavor foods, when you eat food boiled and seasoned. } \\
\text { - Not having salty food often. } \\
\text { - Trying to eat plain food. }\end{array}$ \\
\hline Low energy intake & $\begin{array}{l}\text { - Not having sweet or soft drink often. } \\
\text { - Not having food cooked with oil, such as fries, often. } \\
\text { - Not having fat-rich food often. }\end{array}$ \\
\hline Vegetable/fruit intake & $\begin{array}{l}\text { - Intake frequency of vegetables except for pickles at least } 3 \text { times per day. } \\
\text { - Having greenish yellow vegetables often. } \\
\text { - Having fruits often. }\end{array}$ \\
\hline Healthy eating & $\begin{array}{l}\text { - Not eating food } 2 \mathrm{~h} \text { before you go to bed often. } \\
\text { - Not finishing eating before others often. } \\
\text { - Not having emotional eating. } \\
\text { - Not eating food when you don't feel hungry. } \\
\text { - Not eating more than others. }\end{array}$ \\
\hline
\end{tabular}

activity level was based on frequency of exercise defined as sport, competition, or work for $20 \mathrm{~min}$ or more per day, which gets participants sweaty.

They were surveyed for consciousness of lifestyle modification, such as stage of change and self-efficacy about their lifestyle modifications. The questionnaire was developed for counselling support of lifestyle modification for lifestyle-related disease ${ }^{18)}$, although its validity has not been confirmed. Stage of change ${ }^{16)}$ with regard to healthy lifestyle behaviors was assessed by asking the participants to indicate which of five statements best represented their healthy behaviors in lifestyle (low salt intake, low fat intake, low energy intake, regular exercise). Details are shown in Table 2. Self-efficacy ${ }^{19)}$ was assessed by asking the participants whether they thought that taking action for healthy behaviors in lifestyle (low salt intake, low fat intake, low energy intake, regular exercise) were achievable or not.

\section{Statistical analysis}

We analyzed 185 participants who completed the baseline and post-test questionnaire, to examine the effect of the intervention program. Next, we analyzed 650 participants who answered the baseline questionnaire, including the completion group and the drop-out group who did not complete the post-test, to clarify the difference between participants who were able to continue the pro- gram and those who were not.

Mean and standard deviation were calculated to characterize continuous variables. In the completion group differences between baseline and post-test were determined by McNemar's test. Multiple logistic analyses were used to determine the relationship between consciousness of lifestyle modification at baseline and preferable lifestyle behavior at post-test. In the analysis, the characteristic "stage of change is equal to action or maintenance" for low salt intake, low energy intake, vegetable/fruit intake, healthy eating shows that subjects were those who had initiated preferable dietary behaviors in one of three healthy dietary behaviors, consisting of low salt intake, low fat intake and low energy intake, and the characteristic "stage of change is equal to action or maintenance" for regular exercise shows that subjects were those who had exercised regularly. The characteristic "self-efficacy is equal to achievable" for low salt intake, low energy intake, vegetable/fruit intake, healthy eating shows that subjects were those who thought having preferable dietary behaviors were possible for them in one of three healthy diet behaviors, consisting of low salt intake, low fat intake and low energy intake, and the characteristic "self-efficacy is equal to achievable" for regular exercise shows that subjects were those who thought exercising regularly was possible for them.

Differences between the completion group and the 
Table 2. Stage of change represented five statements with four healthy lifestyle behaviors defined in the present study

\begin{tabular}{|c|c|c|}
\hline Healthy lifestyle behavior & Stage of change & Statement \\
\hline \multirow[t]{5}{*}{ Low salt intake } & Precontemplation & I don't eat a diet with low salt now, and I don't plan to change my diet in the next 6 months. \\
\hline & Contemplation & $\begin{array}{l}\text { Though I don't eat a diet with low salt now, I am thinking about changing my diet, and I will begin to do that in } \\
\text { the next } 6 \text { months. }\end{array}$ \\
\hline & Preparation & Though I don't eat a diet with low salt now, I will change my diet in the next 1 month. \\
\hline & Action & I am eating a diet with low salt now, and I made this change in the past 6 months. \\
\hline & Maintenance & I am eating a diet with low salt now, and I made this change more than 6 months ago. \\
\hline \multirow[t]{5}{*}{ Low fat intake } & Precontemplation & I don't eat a diet with low fat now, and I don't plan to change my diet in the next 6 months. \\
\hline & Contemplation & $\begin{array}{l}\text { Though I don't eat a diet with low fat now, I am thinking about changing my diet, and I will begin to do that in the } \\
\text { next } 6 \text { months. }\end{array}$ \\
\hline & Preparation & Though I don't eat a diet with low fat now, I will change my diet in the next 1 month. \\
\hline & Action & I am eating a diet with low fat now, and I made this change in the past 6 months. \\
\hline & Maintenance & I am eating a diet with low fat now, and I made this change more than 6 months ago. \\
\hline \multirow[t]{5}{*}{ Low energy intake } & Precontemplation & I don't eat a diet with low energy now, and I don't plan to change my diet in the next 6 months. \\
\hline & Contemplation & $\begin{array}{l}\text { Though I don't eat a diet with low energy now, I am thinking about changing my diet, and I will begin to do that in } \\
\text { the next } 6 \text { months. }\end{array}$ \\
\hline & Preparation & Though I don't eat a diet with low energy now, I will change my diet in the next 1 month. \\
\hline & Action & I am eating a diet with low energy now, and I made this change in the past 6 months. \\
\hline & Maintenance & I am eating a diet with low energy now, and I made this change more than 6 months ago. \\
\hline \multirow[t]{5}{*}{ Regular exercise } & Precontemplation & I don't exercise regularly now, and I don't plan to exercise regularly in the next 6 months. \\
\hline & Contemplation & $\begin{array}{l}\text { Though I don't exercise regularly now, I am thinking about exercising regularly, and I will begin to do that in the } \\
\text { next } 6 \text { months. }\end{array}$ \\
\hline & Preparation & Though I don’t exercise regularly now, I will exercise regularly in the next 1 month. \\
\hline & Action & I am exercising regularly now, and I made this change in the past 6 months. \\
\hline & Maintenance & I am exercising regularly now, and I made this change more than 6 months ago. \\
\hline
\end{tabular}

drop-out group were determined by unpaired Student's $t$ test for continuous variables and by $\chi^{2}$ test for categorical variables. Logistic regression analysis adjusting for age was used to investigate the probability of being in the completion group versus the drop-out group and the odds ratio was calculated with a $95 \%$ confidence interval. Next, BMI category, current smoking and habitual drinking were entered into the regression model, and multiple logistic regression analysis was performed.

In all tests, values of $p<0.05$ of two-tailed test were considered significant. All analyses were performed using the SPSS 15.0J for Windows (SPSS Inc., Tokyo, Japan).

\section{Results}

\section{Participants' characteristics}

The participants' characteristics including distributions of each category for BMI, smoking and habitual drinking are shown in Table 3. The average age in the completion group was significantly higher than that in the dropout group for men and women. The proportion of men whose BMI was $25 \mathrm{~kg} / \mathrm{m}^{2}$ or over in the completion group was significantly lower than that in the drop-out group and the same is true of the proportion of men who were current smokers. No other significant differences were seen between the completion group and the drop-out group in women.

\section{Effects of the program}

No significant differences were found in the average of BMI and the proportion of participants who were overweight between baselines and post-test in men and women (data not shown). The changes of self-reported healthy lifestyle behaviors and consciousness between baseline and post-test in the completion group are shown in Table 4. In men, the proportion of those who had more healthy dietary behaviors concerning low energy intake at post-test was significantly higher than that at baseline and the same is true of the proportion of those who exercise $2 \mathrm{~d}$ or more per week. In women, the proportion of those who had more healthy dietary behaviors concerning low salt intake at post-test was significantly higher than that at baseline and the same was true of the proportion of those who exercise $2 \mathrm{~d}$ or more per week.

In men, the proportion of those who were in the action or maintenance stages of change, that is, who had initiated healthy lifestyle behaviors concerning low salt intake at post-test was significantly higher than that at baseline, and the same was true of the proportion of those who had been regularly exercising. In men, the proportion of those who had self-efficacy concerning low salt intake was significantly increased after intervention compared with that at baseline. No significant changes were found in other lifestyle behaviors and consciousness factors between baseline and post-test. 
Table 3. The participants' characteristics at baseline

\begin{tabular}{|c|c|c|c|c|c|}
\hline & & Total & Completion group & Drop-out group & $p$ value \\
\hline Participants & $\mathrm{n}$ & 650 & 185 & 465 & \\
\hline Age & mean (SD) (years) & $40.2(10.2)$ & $43.5(10.1)$ & $38.9(10.0)$ & $<0.001^{\mathrm{a}}$ \\
\hline Men & $\mathrm{n}(\%)$ & $391(100 \%)$ & $121(30.7 \%)$ & $270(69.1 \%)$ & \\
\hline Age & mean (SD) (years) & $44.6(8.8)$ & $47.2(8.0)$ & $43.4(8.9)$ & $<0.001^{\mathrm{a}}$ \\
\hline 40 yr old $\leq$ & $(\%)$ & 69.3 & 83.5 & 63.0 & $<0.001^{\mathrm{b}}$ \\
\hline Body mass index & mean $(\mathrm{SD})\left(\mathrm{kg} / \mathrm{m}^{2}\right)$ & $24.4(3.0)$ & $24.1(2.8)$ & $24.6(3.1)$ & $0.136^{\mathrm{a}}$ \\
\hline $25 \mathrm{~kg} / \mathrm{m}^{2} \leq$ & (\%) & 36.8 & 28.9 & 40.4 & $0.030^{\mathrm{b}}$ \\
\hline Current smoker ${ }^{\mathrm{c}}$ & $(\%)$ & 21.5 & 14.9 & 24.4 & $0.033^{\mathrm{b}}$ \\
\hline Habitual drinker ${ }^{d}$ & $(\%)$ & 41.1 & 43.0 & 40.7 & $0.678^{\mathrm{b}}$ \\
\hline Women & $\mathrm{n}(\%)$ & $259(100 \%)$ & $64(24.7 \%)$ & $195(75.3 \%)$ & \\
\hline Age & mean (SD) (years) & $33.7(8.5)$ & $36.5(9.9)$ & $32.7(7.8)$ & $0.007^{\mathrm{a}}$ \\
\hline $40 \mathrm{yr}$ old $\leq$ & $(\%)$ & 22.0 & 37.5 & 16.9 & $0.001^{\mathrm{b}}$ \\
\hline Body mass index & mean $(\mathrm{SD})\left(\mathrm{kg} / \mathrm{m}^{2}\right)$ & $21.1(3.3)$ & $21.9(4.3)$ & $20.9(2.9)$ & $0.100^{\mathrm{a}}$ \\
\hline $25 \mathrm{~kg} / \mathrm{m}^{2} \leq$ & (\%) & 10.0 & 14.1 & 8.7 & $0.217^{\mathrm{b}}$ \\
\hline Current smoker ${ }^{\mathrm{c}}$ & $(\%)$ & 6.6 & 6.3 & 6.7 & $0.907^{\mathrm{b}}$ \\
\hline Habitual drinker ${ }^{d}$ & $(\%)$ & 10 & 9.4 & 10.3 & $0.839^{\mathrm{b}}$ \\
\hline
\end{tabular}

${ }^{a} p$ value was determined by a Student's unpaired $t$-test.

${ }^{\mathrm{b}} p$ value was determined by the $\chi^{2}$ test.

${ }^{\mathrm{c}}$ Current smoker was defined as a participant who currently smokes daily or occasionally.

${ }^{\mathrm{d}}$ Habitual drinker was defined as a participant who takes more than about $20 \mathrm{~g}$ of alcohol per day for $3 \mathrm{~d}$ or more per week.

Table 4. The changes of self-reported healthy lifestyle behaviors and consciousness between baseline and post-test

\begin{tabular}{|c|c|c|c|c|c|}
\hline & & (n) & Baseline $(\%)$ & Post-test (\%) & $p$ value $^{\mathrm{b}}$ \\
\hline \multicolumn{6}{|l|}{ Men } \\
\hline \multicolumn{6}{|l|}{ Healthy lifestyle } \\
\hline Low salt intake $\mathrm{a}^{\mathrm{a}}$ & Score $\geq 6$ points & (120) & 51.7 & 60.8 & 0.052 \\
\hline Low energy intake ${ }^{a}$ & Score $\geq 2$ points & (118) & 55.1 & 67.8 & 0.003 \\
\hline Vegetable/fruit intake & Score $\geq 1$ points & (121) & 59.5 & 67.8 & 0.110 \\
\hline Healthy eating ${ }^{\mathrm{a}}$ & Score $\geq 3$ points & (119) & 69.7 & 73.9 & 0.359 \\
\hline Regular exercise & Frequency $\geq 2 \mathrm{~d} / \mathrm{wk}$ & (121) & 40.5 & 52.9 & 0.014 \\
\hline \multicolumn{6}{|l|}{ Stage of change } \\
\hline Low salt intake & Action or Maintenance & (119) & 44.5 & 60.5 & 0.001 \\
\hline Low fat intake & Action or Maintenance & (118) & 49.2 & 54.2 & 0.405 \\
\hline Low energy intake & Action or Maintenance & (120) & 56.7 & 60.8 & 0.359 \\
\hline Regular exercise & Action or Maintenance & $(120)$ & 22.5 & 35.8 & 0.005 \\
\hline \multicolumn{6}{|l|}{ Self-efficacy } \\
\hline Low salt intake & Achievable & (120) & 55.8 & 72.5 & 0.001 \\
\hline Low fat intake & Achievable & (120) & 61.7 & 67.5 & 0.324 \\
\hline Low energy intake & Achievable & (118) & 63.6 & 71.2 & 0.122 \\
\hline Regular exercise & Achievable & (120) & 60.8 & 67.5 & 0.229 \\
\hline \multicolumn{6}{|l|}{ Women } \\
\hline \multicolumn{6}{|l|}{ Healthy lifestyle } \\
\hline Low salt intake ${ }^{\mathrm{a}}$ & Score $\geq 6$ points & $(60)$ & 63.3 & 75.0 & 0.039 \\
\hline Low energy intake ${ }^{a}$ & Score $\geq 2$ points & (63) & 57.1 & 58.5 & 1.000 \\
\hline Vegetable/fruit intake ${ }^{a}$ & Score $\geq 1$ points & $(63)$ & 66.7 & 74.6 & 0.267 \\
\hline Healthy eating ${ }^{a}$ & Score $\geq 3$ points & (62) & 61.3 & 56.5 & 0.607 \\
\hline Regular exercise & Frequency $\geq 2 \mathrm{~d} / \mathrm{wk}$ & (64) & 25.0 & 39.1 & 0.035 \\
\hline \multicolumn{6}{|l|}{ Stage of change } \\
\hline Low salt intake & Action or Maintenance & (63) & 60.3 & 74.6 & 0.064 \\
\hline Low fat intake & Action or Maintenance & (63) & 47.6 & 60.3 & 0.077 \\
\hline Low energy intake & Action or Maintenance & (63) & 49.2 & 46.0 & 0.815 \\
\hline Regular exercise & Action or Maintenance & (63) & 14.3 & 19.0 & 0.549 \\
\hline \multicolumn{6}{|l|}{ Self-efficacy } \\
\hline Low salt intake & Achievable & (64) & 65.6 & 76.6 & 0.118 \\
\hline Low fat intake & Achievable & (64) & 54.7 & 62.5 & 0.383 \\
\hline Low energy intake & Achievable & (63) & 46.0 & 57.1 & 0.118 \\
\hline Regular exercise & Achievable & (63) & 41.3 & 54.0 & 0.134 \\
\hline
\end{tabular}

a Each scale is coded as "Low" and "High" scores. For low salt intake "Low" refers to scoring under 6 points, "High" refers to scoring at least 6 points.

${ }^{\mathrm{b}} p$ value was determined by a McNemar's test. 
Table 5. The odds ratios for relationship of consciousness about healthy lifestyle behaviors at baseline and being preferable lifestyle behaviors at post-test

\begin{tabular}{|c|c|c|c|c|c|c|c|}
\hline \multirow{2}{*}{\multicolumn{3}{|c|}{$\begin{array}{l}\text { Healthy lifestyle behavior consciousness } \\
\text { at baseline }\end{array}$}} & \multicolumn{5}{|c|}{ Multivariate $^{\mathrm{b}}$} \\
\hline & & & \multirow{2}{*}{$\begin{array}{l}\text { Low salt } \\
\text { intake }\end{array}$} & \multirow{2}{*}{$\begin{array}{l}\text { Low energy } \\
\text { intake }\end{array}$} & \multirow{2}{*}{$\begin{array}{c}\text { Vegetable } \\
\text { /fruit intake }\end{array}$} & \multirow{2}{*}{$\begin{array}{c}\text { Healthy } \\
\text { eating }\end{array}$} & \multirow{2}{*}{$\begin{array}{l}\text { Regular } \\
\text { exercise }\end{array}$} \\
\hline Men & & (Reference) & & & & & \\
\hline Stage of change & Action or Maintenance & (Precontemplation or Contemplation or Preparation) & $\mathrm{NS}^{\mathrm{a}}$ & $\begin{array}{c}8.37 * * \\
(2.62,26.73)\end{array}$ & $\begin{array}{c}3.65^{*} \\
(1.33,10.04)\end{array}$ & $\begin{array}{c}2.61 \\
(0.85,7.99)\end{array}$ & $\begin{array}{c}11.08 * * \\
(3.00,40.91)\end{array}$ \\
\hline Self-efficacy & Achievable & (Not achievable) & $\begin{array}{c}4.72^{* *} \\
(1.56,14.27)\end{array}$ & $\begin{array}{c}7.06^{* *} \\
(2.06,24.19)\end{array}$ & $\begin{array}{c}3.31^{*} \\
(1.15,9.45)\end{array}$ & $\begin{array}{c}4.42 * \\
(1.39,14.10)\end{array}$ & $\begin{array}{c}4.47^{* *} \\
(1.95,10.22)\end{array}$ \\
\hline \multicolumn{8}{|l|}{ Women } \\
\hline Stage of change & Action or Maintenance & (Precontemplation or Contemplation or Preparation) & $\begin{array}{c}66.15^{*} \\
(5.84,748.94)\end{array}$ & $\begin{array}{c}30.91 * * \\
(2.77,344.79)\end{array}$ & $\begin{array}{c}2.62 \\
(0.55,12.44)\end{array}$ & $\begin{array}{c}4.36 \\
(0.90,21.15)\end{array}$ & $\begin{array}{c}7.66^{*} \\
(1.30,45.11)\end{array}$ \\
\hline Self-efficacy & Achievable & (Not achievable) & $\begin{array}{c}7.07 * \\
(1.48,33.79)\end{array}$ & $\begin{array}{c}5.02 * \\
(1.20,21.06)\end{array}$ & $\begin{array}{c}2.11 \\
(0.50,8.94)\end{array}$ & $\begin{array}{c}5.05^{*} \\
(1.18,21.63)\end{array}$ & $\mathrm{NS}^{\mathrm{a}}$ \\
\hline
\end{tabular}

$* p<0.05 * * p<0.01$.

a NS: not significant.

b Age, BMI category, smoking and habitual drinking were adjusted to obtain the multivariate odds ratio.

" The characteristic "stage of change is equal to action or maintenance" to low salt intake, low energy intake, vegetable/fruit intake, healthy eating shows that subjects were those who had initiated preferable dietary behaviors in one of three healthy dietary behaviors, that was low salt intake, low fat intake and low energy intake, and the characteristic "stage of change is equal to action or maintenance" to regular exercise shows that subjects were those who had exercised regularly.

d The characteristic "self-efficacy is equal to achievable" to low salt intake, low energy intake, vegetable/fruit intake, healthy eating shows that subjects were those who thought having preferable dietary behaviors were possible for them in one of three healthy diet behaviors, that was low salt intake, low fat intake and low energy intake, and the characteristic "self-efficacy is equal to achievable" to regular exercise shows that subjects were those who thought exercising regularly was possible for them.

\section{Relationship between consciousness and behaviors on healthy lifestyle}

The odds ratios for relationship of consciousness about healthy lifestyle behaviors at baseline and being preferable lifestyle behaviors at post-test are shown in Table 5 . The action or maintenance stage of change of any healthy lifestyle behavior at baseline was significantly and positively associated with the more preferable category for low energy intake, regular exercise in both men and women, for vegetable/fruit intake in men, and for low salt intake in women. Having higher self-efficacy of any healthy lifestyle behavior at baseline was significantly and positively related to being in the more preferable category for low salt intake, low energy intake and healthy eating in men and women, and for vegetable/fruit intake and regular exercise in men.

Differences in consciousness and behaviors related to healthy lifestyle between the completion and the drop-out group

The odds ratios of belonging to the completion group able to complete the program by self-reported healthy lifestyle behaviors and consciousness are shown in Table 6. Multiple logistic regression analyses showed that the men who had more healthy eating were $2.0(95 \% \mathrm{CI}$ $1.2,3.4)$ times more likely to be in the completion group compared with those who had less healthy eating, and the women who had more vegetable/fruit intake were 2.1 (95\% CI 1.1, 3.8) times more likely to be in the completion group compared with those who had less vegetable/fruit intake. The men who had initiated healthy lifestyle behaviors, that is, those who were at the action or maintenance stage of change concerning low energy intake, were $2.4(95 \%$ CI $1.5,3.9)$ times more likely to be in the completion group compared with those who had no action healthy lifestyle behaviors concerning low energy intake. No significant associations were found in other lifestyle behaviors and consciousness factors.

\section{Discussion}

The aim of this study was to determine the effectiveness of a computer-tailored lifestyle modification support tool developed for use by employees. The program led to the significant improvements of lifestyle behaviors (regular exercise in both men and women, low energy intake in men, low salt intake in women). Furthermore, it had a preferable effect on stage of change about dietary habits of low salt intake and exercise and self-efficacy of low salt intake in men. The results of the present study suggest a possibility that the program had a positive effect on participants' lifestyle behaviors. In addition, the stage of change and self-efficacy for lifestyle modifications at baseline had positive relationships with preferable lifestyle behaviors at post-test in our study.

Our results concur with previous reports of fully automated computer-tailored intervention at the workplace having preferable effects on dietary behaviors ${ }^{20,21)}$ and physical activity ${ }^{21,22)}$. Araki et al. reported that in the control trial of drinking behavior modification at the workplace, face-to-face health education was more effective than an e-mail program. However, they noted the 
Table 6. The odds ratios of belonging to the completion group by self-reported healthy lifestyle behaviors and consciousness at baseline

\begin{tabular}{|c|c|c|c|c|}
\hline & & & $\begin{array}{l}\text { Age-adjusted } \\
\text { OR }(95 \% \mathrm{CI})\end{array}$ & $\begin{array}{l}\text { Multivariate }{ }^{\mathrm{b}} \\
\text { OR }(95 \% \mathrm{CI})\end{array}$ \\
\hline Men & & (Reference) & & \\
\hline \multicolumn{5}{|l|}{ Healthy lifestyle } \\
\hline Low salt intake & Score $\geq 6$ points & (Score $<6$ points) & $1.50(0.97,2.34)$ & $1.39(0.89,2.18)$ \\
\hline Low energy intake ${ }^{a}$ & Score $\geq 2$ points & (Score $<2$ points) & $1.57(1.00,2.48)$ & $1.40(0.87,2.26)$ \\
\hline Vegetable/fruit intake ${ }^{a}$ & Score $\geq 1$ points & (Score $<1$ points) & $1.48(0.94,2.32)$ & $1.37(0.87,2.17)$ \\
\hline Healthy eating ${ }^{\mathrm{a}}$ & Score $\geq 3$ points & (Score $<3$ points) & $2.17(1.36,3.49)^{* *}$ & $2.02(1.22,3.36)^{* *}$ \\
\hline Regular exercise & Frequency $\geq 2 \mathrm{~d} / \mathrm{wk}$ & (Frequency $<2 \mathrm{~d} / \mathrm{wk}$ ) & $1.78(1.12,2.84)^{*}$ & $1.74(1.08,2.79)^{*}$ \\
\hline \multicolumn{5}{|l|}{ Stage of change } \\
\hline Low salt intake & Action or Maintenance & (Precontemplation or Contemplation or Preparation) & $1.22(0.78,1.92)$ & $1.18(0.75,1.86)$ \\
\hline Low fat intake & Action or Maintenance & (Precontemplation or Contemplation or Preparation) & $1.48(0.93,2.35)$ & $1.43(0.89,2.29)$ \\
\hline Low energy intake & Action or Maintenance & (Precontemplation or Contemplation or Preparation) & $2.53(1.60,3.98)^{* *}$ & $2.40(1.47,3.93)^{* *}$ \\
\hline Regular exercise & Action or Maintenance & (Precontemplation or Contemplation or Preparation) & $1.80(1.02,3.19)^{*}$ & $1.61(0.89,2.89)$ \\
\hline \multicolumn{5}{|l|}{ Self-efficacy } \\
\hline Low salt intake & Achievable & (Not achievable) & $1.04(0.67,1.62)$ & $0.99(0.64,1.56)$ \\
\hline Low fat intake & Achievable & (Not achievable) & $1.28(0.81,2.02)$ & $1.25(0.79,1.98)$ \\
\hline Low energy intake & Achievable & (Not achievable) & $1.59(1.01,2.51)^{*}$ & $1.49(0.93,2.38)$ \\
\hline Regular exercise & Achievable & (Not achievable) & $0.85(0.54,1.33)$ & $0.80(0.50,1.27)$ \\
\hline \multicolumn{5}{|l|}{ Women } \\
\hline \multicolumn{5}{|l|}{ Healthy lifestyle } \\
\hline Low salt intake ${ }^{\mathrm{a}}$ & Score $\geq 6$ points & (Score < 6 points) & $0.86(0.47,1.59)$ & $0.89(0.48,1.66)$ \\
\hline Low energy intake ${ }^{a}$ & Score $\geq 2$ points & (Score $<2$ points) & $1.33(0.74,2.37)$ & $1.35(0.75,2.43)$ \\
\hline Vegetable/fruit intake ${ }^{a}$ & Score $\geq 1$ points & (Score $<1$ points) & $2.07(1.14,3.77)^{*}$ & $2.08(1.14,3.80)^{*}$ \\
\hline Healthy eating ${ }^{a}$ & Score $\geq 3$ points & (Score $<3$ points $)$ & $1.36(0.75,2.44)$ & $1.45(0.79,2.66)$ \\
\hline Regular exercise & Frequency $\geq 2 \mathrm{~d} / \mathrm{wk}$ & (Frequency $<2 \mathrm{~d} / \mathrm{wk}$ ) & $1.00(0.51,1.95)$ & $0.99(0.50,1.93)$ \\
\hline \multicolumn{5}{|l|}{ Stage of change } \\
\hline Low salt intake & Action or Maintenance & (Precontemplation or Contemplation or Preparation) & $1.31(0.73,2.35)$ & $1.35(0.74,2.47)$ \\
\hline Low fat intake & Action or Maintenance & (Precontemplation or Contemplation or Preparation) & $1.39(0.77,2.50)$ & $1.40(0.78,2.52)$ \\
\hline Low energy intake & Action or Maintenance & (Precontemplation or Contemplation or Preparation) & $1.66(0.93,2.98)$ & $1.76(0.96,3.20)$ \\
\hline Regular exercise & Action or Maintenance & (Precontemplation or Contemplation or Preparation) & $1.27(0.52,3.12)$ & $1.26(0.51,3.10)$ \\
\hline \multicolumn{5}{|l|}{ Self-efficacy } \\
\hline Low salt intake & Achievable & (Not achievable) & $0.98(0.53,1.80)$ & $0.99(0.53,1.84)$ \\
\hline Low fat intake & Achievable & (Not achievable) & $1.39(0.78,2.49)$ & $1.41(0.79,2.54)$ \\
\hline Low energy intake & Achievable & (Not achievable) & $0.95(0.53,1.69)$ & $0.96(0.53,1.76)$ \\
\hline Regular exercise & Achievable & (Not achievable) & $0.84(0.47,1.51)$ & $0.84(0.47,1.52)$ \\
\hline
\end{tabular}

$* p<0.05 * * p<0.01$.

a Each scale is coded as "Low" and "High" scores. For low salt intake "Low" refers to scoring under 6 points, "High" refers to scoring at least 6 points.

${ }^{\mathrm{b}}$ Age, BMI category, smoking and habitual drinking were adjusted to obtain the multivariate odds ratio.

possibility that the face-to-face approach was superior to the e-mail approach in their study because of self-monitoring, goal setting process and timely feedback ${ }^{23)}$. Kroeze et al. reviewed randomized trials on the effectiveness of computer-tailored education on physical activity and dietary behaviors, and concluded that more research was needed to identify the mechanisms underlying successful computer tailoring ${ }^{24)}$.

Computer-tailored nutrition and health education has addressed various ranges using computer technology, defined as first and second generation intervention ${ }^{25}$. In first generation intervention, written questionnaires are often used to perform diagnosis, and tailored feedback takes the form of printed matter, while the computer program are used only for analysis of the diagnosis and selection of appropriate feedback based on decision rules. In second generation intervention, an interactive computer program is used, so the participant directly inputs their information such as diagnosis, results of self-monitoring, and gets feedback on the computer screen. In Japan, of these two kind of computer-tailored interventions, previous studies ${ }^{9-11)}$ of computer-tailored nutrition interventions mainly referred to the former rather than the latter, although Kubota et al. developed a health education program utilizing the e-mail function of mobile phones and reported the feasibility of the program without a physical meeting among the subscribers ${ }^{26}$. In Japan, computer technology has infiltrated many aspects of daily life. As of December 2006, it was estimated that internet users totalled 87 million people ${ }^{27)}$. Second generation interventions like the program in our study have the potential to spread rapidly.

Our study had several limitations. First, the response rate to the post-test questionnaire was limited, that was $28.5 \%$. To explore the feasibility of the computer-based lifestyle modification support program in real settings, we 
did not make an attempt to increase the response rates. According to the self-reported questionnaire on the availability of the program from some participants, problems in accessing the menu and input of the record were reported (data not shown). However, Sato et al. reported a follow up rate of primary preventive activities for lifestylerelated disease at a worksite after 2 months of just $18.0 \%{ }^{28)}$. Takahashi et al. reported that a systematic review of lifestyle intervention for health promotion of older adults showed a low drop-out rate when the intervention program targeted people who had health risks or who had diseases at clinics, hospitals, and worksites ${ }^{29}$. In this study we targeted employees irrespective of health risk, so we think that the response rate was not unacceptably low. Nevertheless we need to find ways to decrease the drop-out rate if we are to increase the effect of this program, because those who dropped-out tended to have more lifestyle problems compared with those who completed the program. Second, it was designed as a prepost test study lacking a control group, and the participants were volunteers. These might have influenced the results, because of the possibility that there was a stronger motivation to modify lifestyle behaviours among participants than there was among non participants. Furthermore, there was a possibility that the more participants had prepared goods for starting lifestyle modification, such as a pedometer, at baseline. In addition, we could not deny social desirable bias in participants who completed the program. Third, the four workplaces in our study had 500 or more employees, and that may have influenced the external validity of our results. According to the establishment and enterprise census of 2006, Japan had 5.7 million establishments, and $0.2 \%$ of them had 300 employees or more. Previous studies have reported that health status of employees in small- and medium-sized companies differs from that in large companies in $\mathrm{Japan}^{30)}$. Fourth, the study period was 4 months of the medium value. Considering the follow-up duration, the long term effect of the present findings remains unknown. Conclusions from this study should be generalized with caution because of possible bias. Further studies, including a comparison of the impact of the program with a control group without the program and a follow-up of the drop-out group to clarify differences from the completion group, are needed to demonstrate the conclusions more clearly.

In conclusion, the results of the present study suggest a possibility that the program, utilizing a computer-tailored lifestyle modification support tool developed for use by employees, had a positive effect on participants' lifestyle behaviors in Japanese workplaces. The degree to which our results generalize to effects of the program is unclear but examination to develop more efficient and effective programs is warranted.

\section{Acknowledgements}

We are grateful to all the volunteers who participated in this study. This work was supported by Secom Science and Technology Foundation, Japan.

\section{References}

1) Health and welfare statistic association (2008) Journal of health and welfare statistics 55, 79 (in Japanese).

2) Statistic Bureau. Labour force survey, 2006. http://www. stat.go.jp/data/roudou/report/2006/ft/pdf/summary.pdf. Accessed March 19, 2008.

3) Arao $T$, Oida $Y$, Maruyama $C$, Muto $T$, Sawada $S$, Matsuzuki H, Nakanishi Y (2007) Impact of lifestyle intervention on physical activity and diet of Japanese workers. Prev Med 45, 146-52.

4) Shimizu T, Horiguchi I, Kato T, Nagata S (2004) Relationship between an interview-based health promotion program and cardiovascular risk factors at Japanese companies. J Occup Health 46, 205-12.

5) Takata $Y$, Nakanishi R, Isoda $C$, Niino $M$, Maeda $Y$ (2003) The effect of a health promotion program at the worksite-An approach to hyperlipoproteinemia in workers before middle age. San Ei Shi 45, 43-9 (in Japanese).

6) Muto T, Yamaguchi K (2001) Evaluation of multicomponent workplace health promotion program conducted in Japan for improving employees' cardiovascular disease risk factors. Prev Med 33, 571-7.

7) Kunitsuka K, Yamatsu K, Adachi Y (2002) A correspondence behavioral approach for 6 lifestyle's improvements in a workplace. Nippon Koshu Eisei Zassi 49, 525-34 (in Japanese).

8) Hoshimoto M, Koyama Y, Koike A, Kimura-Kato Y, Maruyama A, Nakajima N, Kawai S, Takayama S (2006) Effects of interactive education program to modify the lifestyle of patients with dyslipidemia-Worksite health promotion program-. Japanese Society of clinical sports medicine 14, 352-62 (in Japanese).

9) Adachi Y, Yamatsu K (2004) The structured computertailored behavior change program for obesity. Journal of Japan Society for the Study of Obesity 10, 31-6 (in Japanese).

10) Adachi Y, Tanaka M, Yamatsu K, Ookochi M, Adachi $\mathrm{K}$ (2004) The long-term effects of brief behavioral intervention with a computer-tailored advice in hypertensive factory workers. Jap J Health Promotion 6, 117-22 (in Japanese).

11) Adachi $Y$, Sato $C$, Yamatsu $K$, Ito $S$, Adachi $K$, Yamaguchi $T$ (2007) A randomised control trial on the long-term effects of a 1-month behavioral weight control program assisted by computer tailored advice. Behav Res Ther 45, 459-70.

12) Brug J, Steenhuis I, van Assema P, de Vries H (1996) 
The impact of a computer-tailored nutrition intervention. Prev Med 25, 236-42.

13) Campbell MK, Tessaro I, DeVellis B, Benedict S, Kelsey K, Belton L, Sanhueza A (2002) Effects of a tailored health promotion program for female blue-collar workers: health works for women. Prev Med 34, 313-23.

14) Nakade M, Muto T, Hashimoto M, Haruyama Y (2006) Internet-based education program of nutrition as a workplace health promotion tool-A review of the literature. International Congress Series 1294, 135-8.

15) Secom Medical System Corporation. Health up Navi. http://medical.secom.co.jp/yobou/navi/index.html. Accessed May 19, 2008.

16) Prochaska JO, Dicremente CC, Norrcross JC (1992) In search of how people change. Applications to addictive behaviours. Am Psychol 47, 1102-14.

17) Japan Society for the Study of Obesity (2006) A guideline for treatment of obesity 2006. Journal of Japan Society for the Study of Obesity 12, 10-5 (in Japanese).

18) Nakamura M, Ikuyama $T$, Suyama $Y$, Date $C$, Adachi Y, Shimai S, Naito Y, Masui S, Honjo K (2001) Report on the research for the establishment of lifestyle modification support methods based on behavioral science and for training of leader, Ministry of health, labor and welfare, Tokyo (in Japanese).

19) Bandura A (1997) Self-efficacy, the exercise of control, 1-35, Freeman and Company, New York.

20) Block G, Block T, Wakimoto D, Block CH (2004) Demonstration of an e-mailed worksite nutrition intervention program. Prev Chronic Dis 1. http://www. pubmedcentral.nih.gov.picrender.fcgi?artid=1277946\& blobtype=pdf. Accessed March 19, 2008.

21) Plotnikoff RC, McCarger LJ, Wilson PM, Loucaides CA (2005) Efficacy of an e-mail intervention for the promotion of physical activity and nutrition behavior in workplace context. Am J Health Promot 19, 422-9.

22) Napolitano MA, Fotheringham M, Tate D, Sciamannna
C, Leslie E, Owen N, Bauman A, Marcus B (2003) Evaluation of an internet-based physical activity intervention: a preliminary investigation. Ann Behav Med 25, 92-9.

23) Araki I, Hashimoto H, Kono K, Matsuki H, Yano E (2006) Controlled trial of worksite health education through face-to-face counseling vs. e-mail on drinking behavior modification. J Occup Health 48, 239-45.

24) Kroeze W, Werkman A, Brug J (2006) A systematic review of randomized trials on the effectiveness of computer-tailored education on physical activity and dietary behaviors. Ann Behav Med 31, 205-23.

25) Brug J, van Assema P (2000) Difference in use and impact of computer-tailored dietary feedback according to stage of change and education. Appetite 34, 285-93.

26) Kubota A, Fujita M, Hatano Y (2004) Development and effects of a health promotion program utilizing the mail function of mobile phones. Nippon Koshu Eisei Zassi 51, 862-73 (in Japanese).

27) Ministry of internal affairs and communications. The current survey of communication utilization, 2006. http://www.johotsusintokei.soumu.go.jp/statistics/data/ 070525_1.pdf. Accessed March 19, 2008.

28) Sato Y, Kanda J, Okumura M, Nishida K (2004) An analysis of the educational effects of group counseling with visual aides: efforts to prevent diabetes in business office setting. San Ei Shi 46, 117-21 (in Japanese).

29) Takahashi M, Kamioka H, Tsutani K, Muto Y (2007) A systematic review of randomized control trials of exercise and lifestyle intervention for the health promotion of older adults-Issues and an effective model of intervention. Jpn J Geriatr 44, 403-14 (in Japanese).

30) Yamataki H, Suwazono $Y$, Okubo $Y$, Miyamoto $T$, Uetani M, Kobayashi E, Nogami K (2006) Health status of workers in small and medium-sized companies as compared to large companies in Japan. J Occup Health 48, 166-74. 